\title{
The Need for Expanding Physician Language Diversity is Too Great to be Left to Chance
}

\author{
Andrea Anderson, MD, FAAFP
}

(J Am Board Fam Med 2022;35:200-202.)

I read with interest Eden et al's recent policy brief detailing the numbers of family physicians who report delivering care in diverse languages. ${ }^{1}$ Their findings seem timely and accurate. Step onto the street of many major US cities, and one is likely to hear a myriad of languages used in conversations at neighborhood coffee shops, announcements on public transportation, gate change warnings at the airport, or emerging from the car radio of your summoned rideshare vehicle. Perhaps a diverse language is used in your own home. If this is the case, you are not alone. According to an analysis of 2018 Census Bureau data, the Center for Immigration Studies found that 67.3 million residents over the age of 5 in the United States speak a language other than English at home, a number equal to the entire population of France. From an even greater perspective, this means that $21.9 \%$ of US residents report speaking primarily in a foreign language at home. ${ }^{2}$

State-specific data illuminate this rate of change even further. In nine states, more than 1 in 4 residents now speaks a language other than English at home. These 9 states account for two-thirds of all foreign-language speakers. California, Texas, and New Mexico lead states where more than a quarter of the population speaks a non-English language at home. However, several states like Nevada, Georgia, and North Carolina have rapidly increasing nonEnglish speaking populations. The take-home

School of Medicine and Health Sciences, The George Washington University, Washington, DC 20052 (AA).

Funding: None

Conflict of interest: None.

Corresponding author: Andrea Anderson, MD, $2120 \mathrm{~L}$ St. NW, Suite 450, Washington, DC 20037. (E-mail: aanderson3125@email.gwu.edu)

\section{See Related Article on Page 5.}

message is that we as a society are becoming increasingly diverse in our language and cultural expression.

Regarding health care, research shows that patients have better health outcomes when working with language-concordant health professionals. ${ }^{3}$ This language concordance should not be viewed as simply a perk; instead, it is quickly becoming an essential aspect of our care delivery. My own anecdotal experience confirms this, at least with regards to comfort and trust. I spent the majority of my career to date practicing clinically and administratively, almost exclusively in Spanish in a large urban center with a significant Spanish-speaking Central American population. Our center was a Federally Qualified Health Center (FQHC) with over 30 languages represented in the patient population and among the staff. I recall the almost palpable relief the patients would express verbally and with their body language when they discovered we shared language concordance in Spanish. They were often more willing to genuinely describe their health concerns or ask or answer uncomfortable and nuanced personal questions. Although clinicians are encouraged to use interpreter services where applicable, the satisfaction and connection are often greater when the clinician can speak directly with the patient in the patient's primary language. ${ }^{3,4}$ Though I am not a native Spanish speaker, I have worked at consistently improving my Spanish fluency, similar to how we as physicians have to consistently work on things that may not come naturally like EKG reading, acid/base interpretation, or any other important aspect of our professional care of patients. It is part of the social contract that we enter into with society, the lifelong learning that we must devote ourselves to as health professionals. Building on a basic foundation in Spanish that I received in high school, I have 
achieved advanced Spanish proficiency in several ways. Some examples include daily practice with Spanish conversation workbooks in medical school, completing an international elective fourth-year rotation in Central America, and electing residency training in a county hospital with a significant Spanish-speaking population. For additional post GME practice, I used my CME funding toward professional Spanish conversation classes for the first 5 years or so of my attending career. Finally, I sought as many opportunities for Spanish language exposure and immersion as I could, even involving my patients in my "Spanish word of the day" challenge. Achieving proficiency must be viewed as a long game. However, I found this engenders increased trust in the doctor-patient relationship I enjoy with my patients and really demonstrates my commitment to cultural competency and proficiency. This is consistent with data that shows that increased language concordance increases everything from trust, understanding of disease presentation, and understanding of and compliance with treatment plans. ${ }^{3}$ Trust is important in all aspects of health care but extremely important and fragile when working with communities of color who historically have suffered mistreatment and trauma in the medical community. In all, this is an example of the nuanced range of differences of simply "delivering" care in another language and true language concordance in care delivery. The latter is what we need to work toward as a profession.

We know that the population of non-English speakers is growing in the US. I would like to propose the following recommendations to increase language capacity among the Family Medicine physician workforce, ultimately with a view toward improved health outcomes.

1. Obtain more stratified data collection. As mentioned in the policy brief by Eden et al, the American Board of Family Medicine (ABFM) Family Medicine Certification Examination registration questionnaire only allows two options for respondents who select yes to providing care in a language other than English "Spanish" or "Other". However, census data shows that several languages other than Spanish are rising to prominence in the US population. Our data collection should include specific choices of leading languages proportional to their prominence in the society. The questionnaire should include the ability to further stratify the "Other" category into languages such as Chinese, Tagalog, Vietnamese, Arabic, and French. ${ }^{1}$ These are the most represented languages in the US after English and Spanish and would give a better snapshot of our Family Medicine workforce's linguistic capacity.

2. Consider querying for proficiency rather than simple care delivery. The ABFM registration questionnaire does not give the respondents the ability to self-report their language proficiency. This data would help inform the ability of physicians to truly connect and communicate effectively with patients. This would provide a more accurate picture of the linguistic depth of our workforce. Currently, the questions ask about care delivery in a language other than English. As Eden et al. point out could mean anything from personal delivery to care delivery via interpretation services. Although interpretation services are essential when working with low English proficiency patients, actual language concordance has demonstrated better health outcomes. ${ }^{3,4}$ A response of yes to a question of personal care delivery in diverse languages can range from very basic vocabulary to fluency in cultural, geographic, and tone appropriate language usage. Revising the question to delineate this data further would be important.

3. Expand residency requirements to emphasize and promote diverse language proficiency. Family Medicine Graduate Medical Education review and certifying bodies should consider encouraging the demonstration of some degree of language proficiency by residents before graduation. Currently, cultural competency measures are often considered along with the professionalism or systems-based practice competency. Language competency could be included in this area, or perhaps a separate competency should be developed which addresses cultural competency. Increased incentivization and support of international clinical rotations for medical students and residents is another suggestion for encouraging the development of a linguistically diverse family medicine workforce.

4. Recruit for a linguistically diverse applicant population along the entire medical pathway. Linguistic diversity should be prioritized 
throughout every aspect of the medical workforce recruitment pathways. It should be advertised and promoted to all applicants that linguistic diversity is highly encouraged and influential for patient outcomes. The goal would be to increase the numbers of linguistically diverse Family Physicians delivering care to patients.

5. Encourage and incentivize linguistic diversity and proficiency. Health care systems should provide or encourage non-English development courses and allow faculty and learner time. For example, my GME training hospital offered a monthly monetary incentive to staff members who demonstrated a moderate proficiency in a non-English language prominent among the patient population. I would advocate for expansion of such programs and support regularly reviewing and surveying the proficiency and regular usage among the staff of that language in patient care.

6. Consider adapting medical education application requirements to include an emphasis on non-English language acquisition and proficiency. Despite all the advancements as a medical community in our understanding of the importance of public and population health, advocacy, cultural competency, and health disparities, the requirements for admission to medical school have remained relatively stagnant since their inception, heavily focused on basic science. ${ }^{5}$ The data presented by Eden et al may help prompt further consideration of requiring other aspects of cultural competency, like diverse language proficiency, as core requirements for medical school admission.
These aspects have significant bearing on actual patient interaction and improved outcomes and should be considered essential preparation tools.

As members of the house of medicine in general and of the family of family medicine, we need to be nimbler in adapting to reflect the needs of the patients that we serve. Appropriately documenting and increasing the prevalence of physicians proficient in non-English languages can directly affect the individual patient and population health outcomes and potentially reduce health disparities.

To see this article online, please go to: http://jabfm.org/content/ 35/1/200.full.

\section{References}

1. Eden AR, Bazemore AW, Morgan ZJ, Jabbarpour Y. Family physicians increasingly deliver care in diverse languages. J Am Board Fam Med 2022;35:5-6.

2. Zeigler K, Camarota SG. 67.3 Million in the United States Spoke a Foreign Language at Home in 2018. The Center for Immigration Studies 2019.

3. Green AR, Nze C. Language-Based Inequity in Health Care: Who Is the "Poor Historian"? AMA Journal of Ethics 2017;19:263-71.

4. U.S. Department of Health and Human Services Office of Minority Health. National Standards for Culturally and Linguistically Appropriate Services (CLAS) in Health and Health Care. Available at: https://thinkculturalhealth.hhs.gov/assets/pdfs/ EnhancedNationalCLASStandards.pdf. Accessed November 5, 2021.

5. American Association of Medical Colleges. Official Guide to Medical School Admissions: How to Prepare for and Apply to Medical School. 2021. Available at: https://store.aamc.org/downloadable/download/ sample/sample_id/471/. Accessed November 5, 2021. 